\title{
Harmony and Help: Recognizing the Impact of Work-Life Balance for Women Leaders
}

\author{
Krystal L. Brue, Ph.D \\ Assistant Professor \\ Department of Business \\ Cameron University \\ Lawton, OK
}

\begin{abstract}
Women leaders operate within multiple roles, managing both work and nonwork obligations. Exploring work-life balance constructs, this study examined role integration, social support sources, and work-family conflict to determine their influence on women leaders. Findings suggested that women leaders felt the benefit of a variety of social support services, but especially from sources external to the organization. Women leaders were diverse in role integration strategies, with respondents largely divided between blurring and segregating their work and nonwork roles. Time-based work-family conflict was slightly more apparent than strain-based conflict. Women leaders also indicated that their work interfered with their family more than their family interfered with their work. Findings provide valuable insights as to how women view work-life balance within their roles as leaders.
\end{abstract}

\section{Introduction}

With the rise of work related stressors, current interest in quality of life concerns, the expansion of work-life balance dialogues, and a desire for women to progress into senior leadership positions, clarifying how work and nonwork obligations are managed is an important component regarding the career and leadership advancement of women (Asirvatham \& Humphries-Kil, 2017; Carlson, Kacmar, \& Williams, 2000; Kossek, 2016; Methot \& LePine, 2016; Phipps \& Prieto, 2016). For employees, the integration, connection, and support between work and family roles can provide mutual opportunities and means for knowledge transfer, encouragement, growth, and cross-role contributions; however, overlapping role demands and responsibilities can also result in increased perceptions of work-life imbalance and work-family conflict (WFC) (McMullan, Lapierre, \& Li, 2018; Michel \& Clark, 2009; Michel, Mitchelson, Pichler, \& Cullen, 2010; Phipps \& Prieto, 2016; Winkel \& Clayton, 2010). Despite studies involving work-life balance, sparse research has been conducted on the impact of WFC within women's leadership development (Kalysh, Kulik, \& Perera, 2016); research clarifying how social support and work-family blurring dynamics influence WFC for women in leadership can enhance women leadership education and should be examined further (Donnelly et al., 2016; Loeffen, 2016; Kalysh et al., 2016; Place \& Varderman-Winter, 2018).

The pressure to grow women in leadership is increasing (Kalysh et al., 2016); yet, women continue to be underrepresented in organizational leadership positions (Ali, Metz, \& Kulik, 2015; Orbach, 2017; Schueller-Weidekamm \& Kautzky-Willer, 2012). This underrepresentation may be perpetuated as men and women experience unique differences regarding their leadership 
development and execution (Bear, Cushenbery, London, \& Sherman, 2017; Ely, Ibarra, \& Kolb, 2011). Recent leadership research has highlighted women's struggles with work-family balance, gender bias cultures, and the expectations of women to assume status quo leadership approaches (Ely et al., 2011; Martin, Edwards, \& Sayers, 2018). Women are better able to develop their unique leadership identity and successfully address their leadership role obligations when they learn from and experience supportive environments and are offered opportunities to balance their diverse obligations (Brue \& Brue, 2018; Debebe, 2011; Orbach, 2017; Schueller-Weidekamm \& Kautzky-Willer, 2012). Organizations which utilize gender diverse leadership and work-life balance interventions report a multitude of benefits including improved performance, organizational branding, and perceptions regarding organizational attractiveness by internal and external stakeholders (Kalysh et al., 2016; Olsen, Parson, Martins, \& Ivanaj, 2016). Connecting work-life balance practices with leadership education allows for further exploration regarding how these dynamics help or hinder women's leadership development. Place and VardemanWinter (2018) conclude that "more exploratory research is needed regarding how work-life balance affects leadership; how gender affects such support; and how such support influences women's leadership trajectories" (p. 168).

This research investigation of work-life balance and women in leadership offers two main contributions to literature. First, this study extends the literature on leadership education by empirically testing how women in leadership perceive social support sources, work-family blurring, and WFC within their roles as leaders. Second, this study clarifies how theoretical frameworks related to work-life balance can be applied to women in leadership positions.

\section{Review of Literature}

Work-Life Balance. Work-life balance is a canopy term involving different social concepts including work, life, family, home, balance, harmony, equilibrium, conflict, enrichment, and integrations (Braun \& Peus, 2018); however, at its nucleus, work-life balance embraces two distinct constructs of balance and conflict (Chang, McDonald, \& Burton, 2010; Kalysh et al., 2016) and focuses on the relationship or equilibrium between work and nonwork roles (Carlson, Grzywacz, \& Zivnuska, 2009; Gregory \& Milner, 2009; Karkoulian, Srour, \& Sinan, 2016). Much of work-life balance research has focused on role stress theory and role scarcity hypotheses (Siu et al., 2013). Initially, work-life balance research focused on the negative consequences of cross-role interference, the paucity of shared resources between home and work, and the harmful effects of balancing multiple roles (Bourhis \& Mekkaoui, 2010; Carlson et al., 2009). This negative spillover examination focused on harmful outcomes including encroachment or "work creep" of work responsibilities conflicting with family needs (Powell \& Greenhaus, 2010), time away from other roles (van der Klis \& Karsten, 2009), role interference (Boyar, Carr, Mosley, \& Carson, 2007), decreased employment satisfaction (Kinnunen, Feldt, Mauno, \& Rantanen, 2010), and decreased family satisfaction (Carlson et al., 2009) resulting in a heightened awareness of the destructive consequences of WFC.

Additional research regarding work-life balance has addressed gender issues (Asirvatham \& Humphries-Kil, 2017; Emslie \& Hunt, 2009; Karkoulian et al., 2016), work-life balance within highly demanding occupations (Baptiste et al., 2017; Schueller-Weidekamm \& KautzkyWiller, 2012), and organizational initiatives aimed at reducing work-life conflict (Bourhis \& 
Mekkaoui, 2010; French, Dumani, Allen, \& Shockley, 2018; Morgan, Perry, \& Wang, 2018; Yang, Zhang, Kwan, \& Chen, 2018). Recently researchers have (a) identified the plethora of work-family enrichment benefits, (b) focused research away from the conventional strain rolerelationship paradigm, and (c) explored the potential resources gained by seeking greater equilibrium between work and life domains (Chang et al., 2010; DiRenzo, Greenhaus, \& Weer, 2015; Karkoulian et al., 2016).

Termed work-family enrichment, work-family facilitation, or positive "spillover," these concepts incorporate the extent to which skills, experiences, and opportunities, which are developed through participation in one role, benefit a person's other roles (Harrison \& Wagner, 2016; Yang et al., 2018). Researchers, who use this work-family enrichment theoretical framework, describe the extent in which participation, talents, and capabilities extend to promote and address role obligations (Boyar et al., 2007; French et al., 2018; Tang, Kwan, Zhang, \& Zhu, 2016; Toffoletti \& Starr, 2016). As resources, skills, and support develop and operate in one domain, role participation and performance improved in other domains (Baltes, Zhdanova, \& Clark, 2011; French et al., 2018; Matthew, Bulger, \& Barnes-Farrell, 2010; Tang et al., 2016). French et al., (2018) and ten Brummelhuis and van der Lippe (2010) summarize the enrichment perspective by suggesting family support is a source of fulfillment and energy that empowered work performance, facilitates bi-directional skill development, and broadens network and social capital resources. The dyadic nature of work-family crossover between role resources, coupled with the intra-individual resources that are transmitted within an individual, supports the notion that work affects an individual's well-being and family (nonwork) connections affect an individual's performance at work (Bakker \& Demerouti, 2017; Braun \& Peus, 2018; Greenhaus \& Powell, 2006; Kaliannan, Perumal, \& Dorasamy, 2016).

Work-life balance and leadership are intertwined (Braun \& Peus, 2018). Women in management have been encouraged to provide employees with work-life balance interventions, noting the positive long-term effect these concessions have on worker productivity (Kalysh et al., 2016). Additionally, women leaders who provide social support initiatives have acknowledged improved relationships and enhanced job satisfaction with followers (Braun \& Peus, 2018) and reduced WFC for employees (Tang et al., 2016). However, empirical research investigating the relationship between leaders and their personal work-life balance constructs, specifically how women in leadership internally perceive and address their own personal work-life balance, is scarce (Braun \& Peus, 2018; Place \& Vardeman-Winter, 2018).

Work-family conflict. A conflict framework can be seen in much of the initial work-life balance research; Greenhaus and Beutell (1985) initially suggested that WFC occurred when obligations, pressures, actions, and behaviors of one role impeded responsibility fulfillment in another role. Greenhaus and Beutell's definition identified three distinct forms associated with failing to balance work and family obligations: time-based conflict, strain-based conflict, and behavior-based conflict. With each of these conflict dimensions, compliance in one domain yielded compliance difficulties in another domain (Harrison \& Wagner, 2016; Morgan et al., 2018; Odle-Dusseau, Britt, \& Greene-Shortridege, 2012). As an individual cannot physically occupy two roles simultaneously, time-based conflict results from the inability to complete obligations and requirements of a role due to the time devoted to other domains (Barnes, Wagner, \& Ghumman, 2012; Kramer \& Wonjoon, 2015; Greenhaus \& Beutell, 1985; van 
Daalen, Willemsen, \& Sanders, 2006). Strain-based conflict results when the role in one domain spilled over and affects interactions within the other domain (Barnes et al., 2012; Greenhaus \& Beutell, 1985). This type of role strain makes it difficult to fulfill requirements or function effectively in the other role (Allen et al., 2014). Finally, behavioral-strain conflict occurs when actions such as leadership, management, or interpersonal styles that are accepted and even rewarded in one domain became incompatible with behaviors desired in the other domain; this conflict occurs when individuals fail to recognize the need to adjust attitudes, actions, and behaviors between home and work (Greenhaus \& Beutell, 1985; Ng \& Feldman, 2014; Veld, van der Heijden, \& Simeijn, 2016).

In addition to considering the form of WFC, researchers have also considered the direction the conflict is perceived. Potentially WFC could result from individuals' work domains interfering with their home and family responsibilities; termed work interference with family (WIF), this type of conflict occurred when work pressures negatively encroached upon home life (Chang et al., 2010; Michel et al., 2010). Family interference with work (FIW) resulted when family responsibilities affected individuals work roles (Chang et al., 2010; Michel et al., 2010). Considering both the direction and form of WFC, six WFC components have emerged including: time-based WIF, time-based FIW, strain-based WIF, strain-based FIW, behavior-based WIF, and behavior-based FIW (Chang et al., 2010; Michel et al., 2010).

Poorly managed WFC, including WIF and FIW, has resulted in a litany of negative outcomes including career stagnation, elevated stress levels, increased occurrences of anxiety, depression, substance abuse, physical health issues, as well as work and family dissatisfaction, (Asirvatham \& Humphries-Kil, 2017; Hilbrecht, Shaw, Johnson, \& Andrey, 2008; McMullan et al., 2018) Additionally, WFC has been identified as the antecedent to work-life imbalance as well as other organizational employee wellness, including professional burnout, poor organizational citizenship behaviors, turnover, and absenteeism (Al-Qutop \& Harrim, 2011; Chang et al., 2010; Maertz \& Boyar, 2011; Steinmetz, Frese, \& Schmidt, 2008; ten Brummelhus \& van der Lippe, 2010).

Similar to work-life balance, much of the WFC literature is focused outwardly, investigating the moderating role that a leader or leadership approach has on followers' WFC. Leaders provide salient influences on workers/followers based largely on leadership styles used (Morgan et al., 2018). Additionally, leaders who provide supportive resources often mitigate the negative effects of WFC in employees and are noted to have created more work-life balanced working environments for their staff (Adkins \& Premeaux, 2012; Kossek, 2016; Morgan et al., 2018). However, nesting WFC research within women leadership education allows for the opportunity to also examine this topic from a leadership intra-identity perspective.

Social support. Social support comprises the appraisal, emotional, instrumental, and informational resources provided to an individual which frequently reduces stress and improves well-being within a domain (Ferguson, Carlson, Kacmar, \& Halbesleben, 2016; French et al., 2018; Werbel \& Danes, 2010). Social support researchers suggest that individuals acquire and sustain salient resources which are regarded to help realize their goals, enrich their performance, gain new assets, or improve well-being (Cho, \& Tay, 2016; Hakanen, Peeters, \& Perhoniemi, 2011). Motivated by a perceived threat of resource loss, individuals often engaged in behaviors 
designed to hedge further loss (Adkins \& Premeaux, 2012; Hobfoll, 2001). Work ethic, social support, self-efficacy, and stamina are valuable individual resources, which aid in meeting individual domain commitments (Adkins \& Premeaux, 2012; 2014). Examples of resources used to meet role commitments include financial means used to build additional resources, personal qualities such as optimism, leadership, resiliency or emotional strength, access to relevant information, and supportive environments (Alarcon, 2011; Bowling, Alarcon, Bragg, \& Hartman, 2015; Karatepe \& Olugbade, 2009); these perceived tools are often needed to obtain and protect what resources a person has reserved (Alarcon, 2011).

As work intensified, time allocated to work typically amplifies, thus leaving less accessible energy for nonwork responsibilities and greater potential for conflict (Adkins \& Premeaux, 2012; Yang et al., 2018). Previous research confirms that as work hours increase and work control deceases, WFC intensifies; however, supervisor support can help ameliorate worklife balance issues and assuage the stress caused by workloads (Adkins \& Premeaux, 2012; DiRenzo, Greenhaus, \& Weer, 2011; Kossek, 2016). Extending Hobfoll's (2001) definition of resources, Hunter, Perry, Carlson, and Smith (2010) characterize social support resource functions by their ability to help an individual meet a demand or facilitate development. For employees, social support resources are instrumental in solving problems, coping with stress, and promoting goals (Williams, Berdahl, \& Bandello, 2016). Acquiring more resources stems from a desire to improve an individual's surroundings while protecting against a likely loss (Siu et al., 2015).

Comparatively, resource loss results in greater psychological stress than resource gain improves well-being (Kossek, 2016). Prolonged resource depletion stems from an erosion of energy, personal worth, and performance (Alarcon, 2011). Fatigue, lack of personal achievement, and cynicism frequently can lead to resource depletion and burnout, and conversely, sustained resources, even in highly demanding environments, can result in optimum performance and personal accomplishment (Alarcon, 2011; Bakker \& Oerlemans, 2016).

Despite these research findings, little is known regarding the crossover effect of social support on leadership (Yang et al., 2018). Researchers acknowledge that social support promotes employee well-being, reduces stress, improves work and family satisfaction, and bolsters mental and physical health (Bjørnstad, Patil, \& Raanaas, 2016; Crain et al., 2014; French et al., 2018; Webber, \& Fendt-Newlin, 2017); however, research has not clarified the impact of social support on leaders' performance and well-being (Dutta, 2018).

Work-family integration and blurring. A multifaceted relationship exists between work and family roles. Examining the micro-strategies and boundaries used to isolate and integrate work and family domains, Winkel and Clayton (2010) defined boundaries by their permeability and flexibility. Permeability signifies the extent an individual is physically located in one role but mentally occupied with other role obligations, and flexibility denotes the ability of an individual to be removed psychologically or physically from a role to meet another domain's demands (Paustian-Underdahl, Halbesleben, Carlson, \& Kacmar, 2016; Winkel \& Clayton, 2010; Xin et al., 2018). While extreme permeable boundaries can be detrimental when managing work-life balance concerns, accessibility and permeable integration of work and nonwork roles may also offer many benefits including role facilitation and trans-role support 
(Halbesleben, Zellars, Carlson, Perrewé, \& Rotondo, 2010; Xin et al., 2018).

The blurring of work and nonwork boundaries has been propelled by structural developments, such as current labor market changes and social imperatives, such as the desire by individuals to balance home and work obligations (Yates, 2011). The spillover between work and nonwork roles offers both the potential for mutual role facilitation as well as the opportunity for role dissonance; segregation of work and nonwork roles limits knowledge and resource transfer, yet reduces the likelihood of role conflict and cross domain distractions (Hilbrecht et al., 2008; McMullan et al., 2018). Therefore, work-family linkage, boundary characteristics, and role attachment influence the way individuals approach and manage their work-family interface and their professional behaviors (Schieman and Young, 2010; Winkel \& Clayton, 2010).

\section{Theoretical Framework}

Boundary theory, Conservation of Resources (COR) theory, and the job-demands resources (JD-R) model provide unique theoretical perspectives when discussing the impact of work-life balance of women in leadership. Boundary theory focuses on the restrictions or borders individuals utilized when managing the demands between work and family. Permeability of boundaries considers an individual's physical role location with their psychological engagement, while flexibility addresses an individual's ability to be mentally or behaviorally removed from a role in order to meet other role demands (Winkel \& Clayton, 2010). Research utilizing boundary theory confirms that an individual's boundary would be more established in the role viewed as the most critical and that greater time and effort would be allocated to shape the most valued domain (Winkel \& Clayton, 2010). Thus, when individuals integrate their roles, they established the strongest boundary in order to protect the most valuable domain (Winkel \& Clayton, 2010; Schieman and Young, 2010).

COR theory, originally proposed by Hobfoll (1989), suggests that individuals are motivated to secure and maintain support and resources, which were perceived to help them achieve their goals. According to this theory, individuals will secure, conserve, maintain, and expand valued resources in order to accomplish domain obligations (Ferguson et al., 2016; Halbesleben et al., 2010; Hobfoll, 1989, 2001; Seiger \& Wiese, 2009). COR theory offers a valid explanation regarding social support, role accumulation, and role spillover impact on women in leadership. Social support directly influences emotional exhaustion, quality of life issues, and the successful integration and coordination of work and family (Bolino, Harvey, Hsiung, \& LePine, 2015; Halbesleben et al., 2010). A lack of spousal social support resources can perpetuate work-life conflict and affect domain specific strain; conversely, chronic conflict and stress hinders familial support resources (McNall, Scott, \& Nicklin, 2015; Odle-Dusseau et al., 2016; Seiger \& Weise, 2009). Matthews, Bulger, and Barnes-Farrell (2010) suggest the increase in dual-earner couples has led to the necessity of employees to attend to family needs at work, and most working adults give priority to the daily well-being of their families, thus attending to the family's needs prior to work related needs. Applying the COR tenets of spousal support attenuating emotional exhaustion within women in leadership, allows this theory to be applied in a new context. 
Work-life balance research has identified workload, long working hours, and employment strain as crucial antecedents to WFC (Bakker \& Oerlemans, 2016). Family friendly policies, flexible work schedules, and social support have been identified as strategies for reducing the strain and interference between home and work (Bakker \& Oerlemans, 2016). The JD-R model provides an operational framework to examine this strain as well as an application by which to examine how resources ameliorate role strain. Within this model, employment conditions and job characteristics are categorized by the demands and resources they provide to an individual, shaping employment satisfaction, engagement, and burnout (Bakker \& Oerlemans, 2016; Berthelsen, Hakanen, \& Westerlund, 2018). Work/job demands include physical, social, and organizational qualities of a job requiring the physical or mental effort of an individual (Schieman \& Young, 2010; van de Voorde, Veld, \& van Veldoven, 2016). Work stress, workload, role conflict, and managing employment strain are examples of job demands (Bakker \& Oerlemans, 2016; Berthelsen et al., 2018) and are frequent issues that organizational leaders must address. Within the JD-R model, work/job resources includes the personal and organizational cost of performing a job and considers elements such as social support and role autonomy. These support resources help an individual meet role demands and can also act as a catalyst for personal and professional development, including leadership growth (Berthelsen et al., 2018; Schieman \& Young, 2010).

\section{Research Purpose and Questions}

The purpose of this study was to explore social support sources, work-family integration/blurring, and WFC to discover how women perceive these dynamics within their leadership role. Based on leadership and work-life balance literature, three research questions guided this study: (a) is there a relationship between the sources of support for women in leadership and integration or segregation of work and nonwork roles, (b) is WFC influenced by role integration for women in leadership, and (c) what type of WFC is primarily perceived by women in their leadership roles?

Paustian-Underdahl et al. (2016) concluded that the permeability of work and nonwork domains allows for greater transferability of resources. The integration of work and nonwork domains permits resources to be shared between roles, mutually benefiting role obligations, and positively impacting work productivity (Carlson, Ferguson, Kacmar, Grzywacz \& Whitten, 2011; Greenhaus \& Powell, 2006; Paustian-Underdahl et al., 2016). Therefore, based on social support and work-family blurring research, Hypotheses 1 was established.

Hypothesis 1: There is a difference between sources of social support and integration/segregation of work and non-work roles for women leaders.

Greenhaus and Powell (2006) determined that role integration did increase the likelihood of WFC. Additional research (Asirvatham \& Humphries-Kil, 2017; Halbesleben, 2010; OdleDusseau et al., 2012) also suggest that role blurring increases WFC but also allows for easier and repeated resource support and transmission between domains. Hypothesis 2 addresses the relationship between role integration and WFC for women in leadership. 
Hypothesis 2: There is a difference between role integration/segregation and WFC for women leaders.

Work and non-work role integration fosters more WFC (Asirvatham \& Humphries-Kil, 2017; Matthews et al., 2010). Considered the more prevalent form of WFC (Jiang, Luo, \& Kulemeka, 2017), time-based conflict occurs when time applied to one domain drains resources from other domains. Strain-based conflict occurs when stress and strain from one role spills over to other roles, and behavioral-based conflict occurs when behaviors between roles are incompatible (DiRenzo et al., 2011; Jiang et al., 2017). Time-based conflict can have a significant impact of women leaders as they juggle responsibilities between multiple roles, manage work creep and role schedule conflicts, and acknowledge the scarcity of personal and professional time and energy. Hypothesis 3 addresses which type of WFC is more recognized by women leaders.

\section{Hypothesis 3: Time-based WFC will be perceived more than strain-based WFC within} women leaders.

\section{Research Methods and Design}

Participants. For this research, 93 women leaders who were members within a womenonly professional association were identified as potential respondents. A women's only science, technology, engineering, and mathematics group ( 45 members) and as women's only business professional group (48 members) in the south-central United States were identified as potential respondents in the study. Both groups consisted of women practitioners, educators, and industry leaders, whose mission was to expand the growth of women in their perspective industry and profession.

\section{Measures.}

Social support. Social support sources were determined by allowing participants to rank order those individuals they perceived provided them the most support in their leadership role. Participants were asked to rank order the top five individuals; options of individuals who provide support included spouse, significant other, family member, children, women supervisor, male supervisor, mentor within the organization, mentor outside the organization, women co-worker, male co-worker, female friend, male friend, and other. A composite ranking was calculated for each source of support, progressively weighting each support choice (first choice was weighted 5, second choice was weighted 4 , etc.).

In order to compare social support source groups with other work-life balance variables, participants were coded as either primarily receiving support from sources inside or outside of their organization. This was determined based on their individual support source rankings. If the majority of support sources (three or more of the top five) were from within their organization, respondents were coded as primarily benefiting from sources inside the organization. Equally, if three or more of the support sources listed 
were from external sources, participants were coded as primarily benefiting from sources outside of their organization.

Work-family integration/blurring. The Work-Family Integration-Blurring Scale of Desrochers, Hilton, and Larwood (2005) was utilized to evaluate the integration of work and family roles. This four-question assessment allowed participants to compare the separation or integration of work and family domains. Questions included: (a) It is difficult to tell where my work life ends and my family/nonwork life begins; (b) I tend to integrate my work and family/nonwork duties at home; (c) I tend to integrate my work and family/nonwork work duties at work; and (d) In my life, there is a clear boundary between my career and my nonwork roles. Responses from a 5-point Likert scale were evaluated where $1=$ strongly agree, $2=$ somewhat agree, $3=$ neither agree nor disagree, $4=$ somewhat disagree, and 5=strongly disagree.

A composite score was used to represent a total blurring/integration construct by combining participants' responses for the four questions, leaving scores to range from 4 to 20. In order to evaluate blurring groups, data regarding integration and segregation were converted, coding participants as either primarily integrators or segregators. Participants whose total composite score ranged from 4 to 12 were grouped and labeled as integrators and participants whose total composite score ranged from 13 to 20 were grouped and classified as segregators.

Desrochers et al. (2005) reported sufficient internal consistency reliability coefficient (Cronbach's alpha of .76) and evidence of the scale's construct validity regarding the measurement of work-family blurring, hours worked, distractions while working at home, and work-family transitions.

Work-family conflict. Carlson's et al. (2000) WFC scale was used to assess time-based and strain-based conflict and its effect on the homeostasis between home and work. This scale examines time-based, strain-based, and behavioral-based conflict. Only time-based and strain-based responses were compared with women in leadership. Behavioral-based questions were not included in this research as questions addressed issues outside the scope of the study. Carlson et al.'s (2000) WFC scale included items such as "My work keeps me from my family activities more than I would like" and "Due to all the pressures at work, sometimes when I come home I am too stressed to do the things I enjoy" (p. 272). Six time-based WFC questions were asked (three WIF timebased conflict questions and three FIW time-based conflict questions) and six strainbased WFC questions were included (three WIF strain-based conflict questions and three FIW strain-based conflict questions).

Again, a 5-point Likert scale was used allowing respondents to range from 1=strongly agree to 5=strongly disagree. A composite score was used to represent a time and strainbased latent construct by combining participants' responses. Cronbach's alpha of reliability for the Carlson et al. (2000) scale is .83 for time-based family-work interference and .93 for strain based family-work interference (van Daalen et al., 2006).

Procedures. After obtaining research approval, participants were electronically directed to a Qualtrics website to complete the survey. The first two questions of the assessment were designed to establish the respondent's participant criteria and document their willingness to participate in the study. Narrow demographic information was captured including group membership role and career longevity; participants were asked 17 quantitative questions 
regarding types of perceived social support, work-life integration/blurring, and WFC perceptions.

\section{Results}

Of the 93 who were invited to participate, 45 opened and voluntarily completed the survey, indicating a response rate of $48 \%$.

\section{Descriptive Statistics.}

Social Support. Respondents were asked to rank order individuals who provided them the most support within their leadership position. Table 1 displays weighted composite data from perceived sources of social support.

Table 1. Sources of Social Support for Women Leaders

\begin{tabular}{lc}
\hline Sources of Support & Weighted Composite Scores \\
\hline Spouse/SO & 175 \\
Mentor outside org & 90 \\
Female Supervisor & 59 \\
Female Co-worker & 49 \\
Female Friend & 43 \\
Mentor w/in org & 40 \\
Family & 38 \\
Male Supervisor & 19 \\
Male Supervisor & 35 \\
Children & 27 \\
Other & 14 \\
Male Friend & 0 \\
\hline
\end{tabular}

Examining the individuals who provided participants with the greatest perceive support (ranked 1), 38 participants ranked sources external to the organization as their most helpful and seven participants ranked internal organizational sources as most helpful. Twenty-eight of the 45 participants ranked their spouse or significant other as their primary source of support. Four individuals ranked a mentor outside the organization as their primary source of support and 13 participants ranked an outside mentor as their second most supportive source, leaving the external mentors with a total composite rate of 90. The most perceived sources of support for participants in respective order of helpfulness were spouse/significant other, mentor outside the organization, female supervisor, and female coworker.

In order to compare social support with work-family blurring and WFC, participants were coded as either primarily receiving support from outside their work organization or from within their organization. If three or more of the top five support sources listed were internal-organizational sources, participants were coded as primarily benefiting from sources within the organization. Conversely, if three or more of the support sources 
listed were external-organizational sources, participants were coded as primarily benefiting from sources outside the organization. Based on this criteria, 22 (49\%) of the respondents were coded as primarily using external sources, and $23(51 \%)$ were coded as primarily using internal sources.

Work-family integration/blurring. Respondents were asked to respond to four work-family integration/blurring questions. Responses from a 5-point Likert scale were combined to form a composite blurring score; the final question was reverse coded because of its transposed wording. Composite blurring scores $(M=11.02, S D=4.975$, range $=16$, skewness $=.210$ ) were analyzed of the 45 respondents; 27 respondents indicated that they integrate boundaries between work and family roles (with a composite blurring score ranging from 4-12), and 18 indicated that they segregate their work and non-work roles (with a composite blurring score ranging from 13-20). Figure 1 shows the work-family integration/blurring distribution for this study's participants.

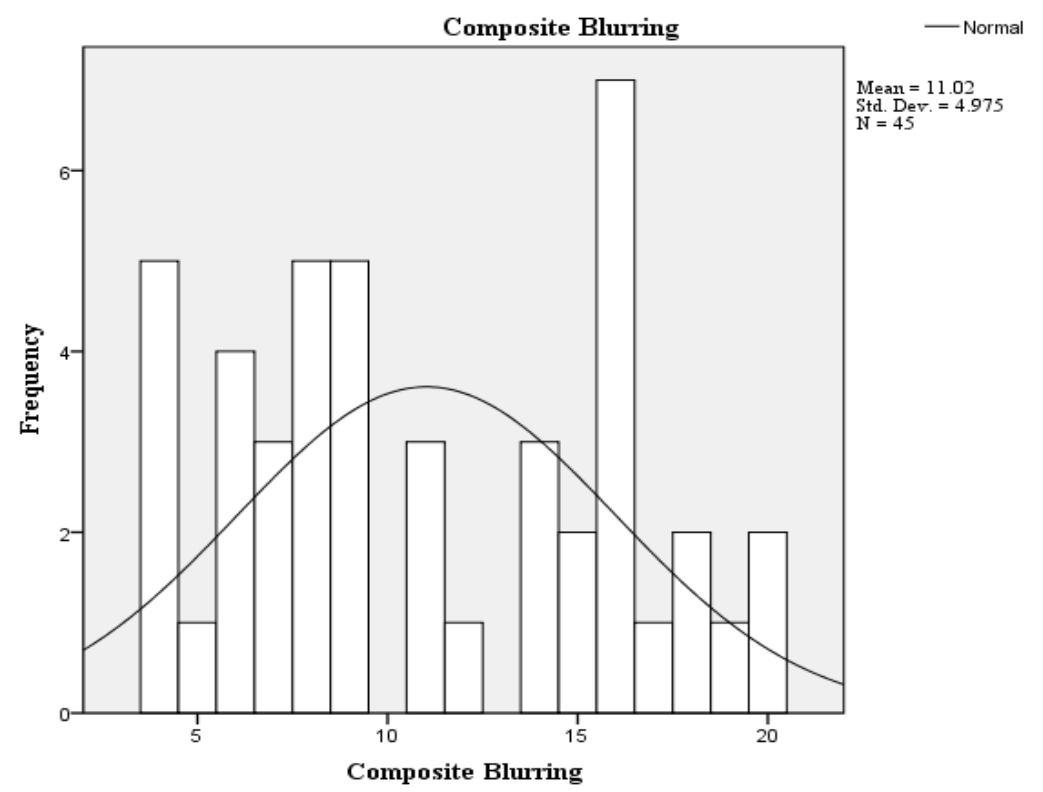

Figure 1. Distribution of Composite Blurring Scores

Work-family conflict. Twelve time-based and strain-based WIF and FIW questions were included in this research. Participants responded using a 5-point Likert scale ranging from "strongly agree" to "strongly disagree." Sub scores from time-based and strain-based WIF and FIW each ranged from 3 to 15. Composite time-based and strain-based WIF/FIW ranged from 6 to 30 each and total WFC ranged from 12 to 60. Results indicated slightly more time-based WFC was perceived $(M=19.56, S D=4.33)$ than strain-based WFC $(M=20.29, S D=3.48)$. The composite total mean for WFC was $39.84, S D=6.72$. Table 2 provides descriptive statistics for all WFC types. 
Table 2. Descriptive statistics regarding WFC

\begin{tabular}{|c|c|c|c|c|c|c|c|}
\hline & \multicolumn{3}{|c|}{ WIF Time FIW Time Total Time } & \multicolumn{3}{|c|}{ NIF Strain FIW Strain Total Strain } & \multirow{2}{*}{$\begin{array}{l}\text { Total } \\
\text { WFC }\end{array}$} \\
\hline & WFC & WFC & WFC & WFC & WFC & WFC & \\
\hline $\mathrm{N}$ Valid & 45 & 45 & 45 & 45 & 45 & 45 & 45 \\
\hline Missing & 0 & 0 & 0 & 0 & 0 & 0 & 0 \\
\hline Mean & 9.47 & 9.96 & 19.56 & 9.27 & 11.02 & 20.29 & 39.84 \\
\hline Median & 10.00 & 10.00 & 20.00 & 9.00 & 12.00 & 20.00 & 40.00 \\
\hline Mode & 7 & 10 & $20^{\mathrm{a}}$ & 8 & 13 & 20 & 40 \\
\hline Std. Deviation & 2.464 & 2.393 & 4.325 & 2.147 & 2.435 & 3.475 & 6.722 \\
\hline Variance & 6.073 & 5.725 & 18.707 & 4.609 & 5.931 & 12.074 & 45.180 \\
\hline Skewness & -.340 & .211 & .018 & .387 & -.462 & .082 & .280 \\
\hline $\begin{array}{l}\text { Std. Error of } \\
\text { Skewness }\end{array}$ & .354 & .354 & .354 & .354 & .354 & .354 & .354 \\
\hline Kurtosis & -.410 & .232 & -.401 & -.396 & -.588 & -.185 & -.121 \\
\hline $\begin{array}{l}\text { Std. Error of } \\
\text { Kurtosis }\end{array}$ & .695 & .695 & .695 & .695 & .695 & .695 & .695 \\
\hline Range & 11 & 11 & 18 & 9 & 10 & 15 & 31 \\
\hline
\end{tabular}

a. Multiple modes exist. The smallest value is shown

Hypothesis Testing. For hypotheses 1 and 2, Mann-Whitney U tests were performed with a significance level of .05 , in order to determine if the compared factors were significantly different. The Mann-Whitney $\mathrm{U}$ is a powerful non-parametric test and is at less risk to give wrongful significant results when data includes extreme values within the investigate sample (Landers, 1981; Siegel \& Castellan, 1988). Non-parametric tests, and specifically the MannWhitney $\mathrm{U}$, are appropriate in research when two groups of data are from the same population and are asymmetrical distributed, when comparison of observations in one group are compared to observations compared in another group, and when the sample size is limited (Nachar, 2008). Viewing data gathered conservatively to ensure greater confidence in any identified relationship and considering non-parametric factors related to the study, the Mann-Whitney U test was performed to determine the first two hypotheses.

Regarding Hypothesis 1, when comparing coded sources of social support ( $M d n=2)$ and composite work-family blurring ( $M d n=9)$, Mann-Whitney $\mathrm{U}$ results indicate that there is evidence to suggest a difference between women in leadership who primarily use internal or external social support and how they integrate or segregate their work and family roles ( $U=77.00, z=-4.015, N_{e x}=22, N_{i n}=23, p=.000,2$-tailed). Table 3 review results of this analysis. Additionally, the composite blurring mean of respondents who primarily used external sources of support was 14; however, the composite blurring mean of respondents who primarily used internal-organizational sources of support was 8.17. Based on results, Hypothesis 1 was accepted as a difference was indicated between sources of support and blurring women leaders. Furthermore, additional analysis determined that women leaders who utilize primarily external sources of support tended to integrate their work-family roles more than women who utilize primarily internal support sources. 
Table 3. Comparison of Support Sources and Composite Blurring

\begin{tabular}{lr}
\hline & Composite Blurring \\
\hline Mann-Whitney U & 77.000 \\
Wilcoxon W & 353.000 \\
Z & -4.015 \\
Asymp. Sig. (2-tailed) & .000 \\
\hline
\end{tabular}

a. Grouping Variable: SS Source

Addressing Hypothesis 2, Mann-Whitney U tests were conducted with composite WFC and WFC subcategories. Table 4 reviews results from each tests and indicates significant results within three WFC subcategories. There is no evidence to support a difference between workfamily integration $(M d n=9)$ and total WFC $(M d n=40)$, total composite stain-based WFC $(M d n=20)$, WIF strain-based WFC ( $M d n=9)$, and FIW strain-based WFC $(M d n=12)$; however, findings indicate that there is evidence to support a difference in the way women leaders who integrate and segregate their roles perceive time-based WFC ( $M d n=20, U=153.00, z=-2.092$, $N_{\text {blu }}=27, N_{\text {seperate }}=18, p=.036,2$-tailed $)$, WIF time-based WFC ( $M d n=10, U=141.50, z=-2.372$, $N_{\text {blur }}=27, N_{\text {seperate }}=18, p=.018,2$-tailed $)$, and FIW time-based WFC $(M d n=10, U=139.00, \mathrm{z}=-$ $2.448, N_{\text {blur }}=27, N_{\text {seperate }}=18, p=.014,2$-tailed). Based on work-family blurring and WFC results, Hypothesis 2 was partially rejected. Total WFC and all strain-based WFC did not indicate that women leaders who integrate their roles perceived differences in WFC. However, women leaders within this study appeared to perceive time-based WFC, including FIW and WIF, differently within their approach as integrators or segregators.

Table 4. Comparison of Blurring and WFC categories

\begin{tabular}{|c|c|c|c|c|c|c|c|}
\hline & $\begin{array}{l}\text { Total } \\
\text { WFC }\end{array}$ & $\begin{array}{l}\text { Total Time } \\
\text { WFC }\end{array}$ & $\begin{array}{l}\text { WIF Time } \\
\text { WFC }\end{array}$ & $\begin{array}{l}\text { FIW Time } \\
\text { WFC }\end{array}$ & $\begin{array}{c}\text { Total Strain } \\
\text { WFC }\end{array}$ & $\begin{array}{l}\text { WIF Strain } \\
\text { WFC }\end{array}$ & $\begin{array}{l}\text { FIW Strain } \\
\text { WFC }\end{array}$ \\
\hline Mann-Whitney U & 175.000 & 153.000 & 141.500 & 139.000 & 213.500 & 182.000 & 238.500 \\
\hline Wilcoxon W & 553.000 & 531.000 & 519.500 & 517.000 & 591.500 & 560.000 & 409.500 \\
\hline $\mathrm{Z}$ & -1.579 & -2.092 & -2.372 & -2.448 & -.687 & -1.434 & -.105 \\
\hline $\begin{array}{l}\text { Asymp. Sig. (2- } \\
\text { tailed) }\end{array}$ & .114 & .036 & .018 & .014 & .492 & .152 & .916 \\
\hline
\end{tabular}

a. Grouping Variable: Blurring Group

Hypothesis 3 proposed that women in leadership would feel the effects of time-based WFC more than strain-based WFC. Time-based WFC $(M=19.56, S D=4.33)$ and strain-based WFC ( $M=20.29, S D=3.48)$ were perceived similarly among respondents, but time-based WFC was recognized as more apparent. Table 5 provides an overview of all WFC constructs. Timebased WIF $(M=9.47)$ was perceived slightly more than time-based FIW $(M=9.96)$. Additionally, strain-based WIF $(M=9.27)$ was perceived more than strain-based FIW $(M=11.02)$. Based on findings, Hypothesis 3 was accepted. 
Table 5. WFC Statistics

\begin{tabular}{lccccc}
\hline & N & Mean & Std. Deviation & Minimum Maximum \\
\hline Total WFC & 45 & 39.84 & 6.722 & 25 & 56 \\
Total Time WFC & 45 & 19.56 & 4.325 & 11 & 29 \\
WIF Time WFC & 45 & 9.47 & 2.464 & 3 & 14 \\
FIW Time WFC & 45 & 9.96 & 2.393 & 4 & 15 \\
Total Strain WFC & 45 & 20.29 & 3.475 & 14 & 29 \\
WIF Strain WFC & 45 & 9.27 & 2.147 & 6 & 15 \\
FIW Strain WFC & 45 & 11.02 & 2.435 & 5 & 15 \\
\hline
\end{tabular}

\section{Evaluation of Findings}

This study adds to women in leadership literature by investigating the unique work-life balance dynamics of social support sources, work-family integration, and WFC. Bringing a comprehensive framework closer for women in leadership, the current research study adds to theory and offers insights for practical development of women leaders. Understanding social support, work-family blurring, and WFC dynamics for women in leadership provides greater potential to aid in the future development of women leaders.

Social Support Sources. Women in leadership received social support from a variety of internal-organizational and external-organizational sources. The two primary sources of social support for respondents were from external sources and included spouses/significant others and mentors outside the organization. These sources appeared to provide women in leadership the potential for safe, private, and confidential information, advice, and support needed to help them progress in their leadership roles. Female supervisors and female co-workers were the most recognized internal-organizational sources of support and were ranked third and fourth in overall helpfulness of support resources. Having shared professional experiences and goals as well as wanting to invest in the organization's human capital likely aided in the development of supervisory and co-worker support sources.

Ruderman \& Ohlott (2005) noted that relational connections, authenticity, selfawareness, and supportive resources are important in the leadership development of women. Women are more likely to progress in their personal leadership development when they are provided opportunities to connect with other women, bolster leadership knowledge, and facilitate self-esteem (Boatwright \& Egidio, 2003). Within this study, women leaders verified the variety of sources of support providing them advice, information, resources, assistance, and encouragement. Findings from this research extends the JD-R model and COR theory (Bakker \& Oerlemans, 2016; DiRenzo et al., 2011, Matthews et al., 2010: Paustian-Underdahl et al., 2018) by suggesting that individuals value the perceived support and encouragement from spouses, co-workers, and mentors regarding their work. Results confirm a COR premise that work and family domain support can equip individuals with increased role performance. Additionally, this research strengthens the JD-R model by suggesting that resources, such as spousal/significant other social support, act as a catalyst for leadership development. Spousal support directly influences stress, emotional fatigue, wellness, and the successful balancing of 
work and family responsibilities (Halbesleben et al., 2010). A lack of spousal social support resources has been found to perpetuate WFC and negatively impact professional productivity and career advancement (Seiger \& Weise, 2009).

Work-Family Integration/Blurring Implications. Within this study, women leaders presented as bimodal in their integration or segregation of roles. Based on the research question regarding clear boundaries between work and home, $40 \%$ indicated strongly or somewhat agreed that they had clear boundaries between work and family roles, and $49 \%$ indicated they strongly or somewhat disagreed that they clearly established boundaries between roles. Findings indicate that women leaders have adapted a personal strategy of role integration which fits their personal preference, dynamic, and situation. Results also suggested a difference between supportive sources and role blurring; women leaders who primarily acknowledged external sources tended to integrate their roles more than women leaders who primarily used internal sources. In addition, women leaders who tended to integrate their roles experienced time-based WFC differently than women who tended to segregate their work and nonwork roles.

Recognizing the importance of boundary and COR theory, Michel et al. (2010) acknowledged individuals who integrate multiple roles often feel the effects of conflicting roles; because all individuals function under a finite amount of resources (e.g. time and energy), family and work roles are often incompatible. Individuals who mentally process role obligations outside of normal spatial or temporal boundaries (doing work at home or working on nonwork tasks at work), allow role demands to invade and permeate other domains (Schieman \& Young, 2010). However, social support and social-capital resources offer key components for individuals aimed at reducing role stressors and buffering the relationship between family and work (Greenhaus \& Powell, 2006; Michel et al., 2010). Approximately half of women leaders within this study allowed for role integration. With role integration, experiences, support, and occurrences in one domain can impact a person's other domains. Purposeful or unintentional blurring of work and nonwork roles appeared to impact within whom they received social support and how respondents perceived time-based WFC.

WFC. Within this sample time-based WFC was slightly more apparent than strain-based WFC. Time-based conflict involves the interference of personal life with work responsibilities, preventing women leaders from effectively performing at work. Strain-based conflict involves feeling fatigued at work due to stress at home, personal demands, or preoccupation with family obligations. WIF (time and strain-based) was perceived more than FIW (time and strain-based) within respondents, indicating the perception that work interferes with family more than family interferes with work. Analysis also suggest that women leaders who primarily integrate their roles perceive time-based WFC differently than women leaders who primarily segregate their roles. This WIF (time and strain-based) predominance may validated Winkel and Clayton's (2010) premise that individuals establish the strongest boundary in order to protect their most valuable domain.

Social support can act as a moderator by directly influencing perceived conflict (Seiger \& Wiese, 2009). COR research has determined that role blurring facilitated increased WFC but social support, moderated by working hours, reduced felt conflict relating to work and family domains (Adkins \& Premeaux, 2012). While this study was small, results support the notion that 
women who integrate their roles perceived more time-based WFC and more work obstacles interfering with family responsibilities.

\section{Limitations and Future Research}

This research adds to the discussion involving women leadership education and work-life balance; examining social support sources, work-family blurring, and WFC through the use of conservative non-parametric tests bolsters confidence in the study's results. Findings confirm that women use a variety of social support sources and primarily seek external sources of support to promote their leadership identify. Time and strain-based conflict is evident, but women leaders acknowledge the stress associated with their inability to complete family role obligations due to time devoted to work obligations. Discussing and acknowledging the potential conflict associated with work and family can help emerging women leaders to be strategic and proactive in establishing their personal work-life balance strategies.

Despite these strengths, research limitations within this study may influence findings. The sample size of 45 participants is small, which could affect the generalizability of findings to other women leaders. The small sample size may also limit the applicability of results and merits additional attention with further research.

This study also used established testing instruments to examine work-family blurring and WFC. While this added a layer of credibility of the study, the use of established surveys may have omitted emerging trends and dynamics within role integration and WFC. The use of other work-life balance instruments would provide additional elucidation and confirmation regarding this topic.

Additionally, this study provides a snapshot view of work-life balance. Examining this dynamic within a longitudinal research project would afford clarity as to the effects of social support, work-family blurring, and WFC to women in leadership roles. Future research should also examine how social support is effectively transmitted to women leaders, what types of social support is most beneficial in the development of women leaders, and what qualities make some social support more helpful than others types and sources.

\section{Conclusion}

The relationship between women leaders and work-life balance dynamics is complex and not fully understood. The purpose of this study was to provide a deeper examination of how women utilize social support sources, work-family blurring, and WFC within their leadership roles. Findings suggest the importance of internal and external support sources for women in leadership and highlight the diversity between women who integrate and segregate their work and nonwork roles. Women in leadership tend to feel more time-based conflict than strain-based conflict. Work obligations also appeared to interfere with family more than family interfered with work obligations. Understanding work-life balance for women leaders will help women to develop a strategy aimed at achieving personal and professional growth as well as the harmony and help associated with work-life balance. 


\section{References}

Adkins, C. L., \& Premeaux, S. F. (2012). Spending time: The impact of hours worked on workfamily conflict. Journal of Vocational Behavior, 80(2), 380-389.

doi:10.1016/j.jvb/2011.09.003

Adkins, C. L., \& Premeaux, S. A. (2014). The Use of Communication Technology to Manage Work-Home Boundaries. Journal of Behavioral \& Applied Management, 15(2), 82-100.

Alarcon, G. M. (2011). A meta-analysis of burnout with job demands, resources, and attitudes. Journal of Vocational Behavior, 79(2), 549-562. doi:10.1016/j.jvb.2011.03.007

Ali, M., Metz, I., Kulik, C. T. (2015). The impact of work-family programs on the relationship between gender diversity and performance. Human Resource Management, 54(4), 553576. doi:10.1002/hrm.21631

Allen, T. D., Lapierre, L. M., Spector, P. E., Poelmans, S. A., O'Driscoll, M., Sanchez, J. I., Cooper, C. L, Antoniou, A., Brough, P., Geurts, S., Kinnunen, U., Pagon, M., Shima, S. $\&$ Woo, J. (2014). The link between national paid leave policy and work-family conflict among married working parents. Applied Psychology: An International Review, 63(1), 528. doi:10.1111/apps. 12004

Al-Qutop, M. Y., \& Harrim, H. (2011). Quality of worklife human well-being linkage: Integrated conceptual framework. International Journal of Business and Management, 6(8), 193205. doi:10.5539/ijbm.v6n8p193

Asirvatham, S., \& Humphries-Kil, M. (2017). Feminist reflections on life in (im)balance, career praxis, and the PRME. International Journal of Management Education, 15(2B), 126137. doi:10.1016/j.ijme.2017.03.005

Bakker, A. B., \& Demerouti, E. (2017). Job demands-resources theory: Taking stock and looking forward. Journal of Occupational Health Psychology, 22(3), 273-285. doi:10.1037/ocp0000056

Bakker, A. B., \& Oerlemans, W. M. (2016). Momentary work happiness as a function of enduring burnout and work engagement. Journal of Psychology, 150(6), 755-778. doi: $10.1080 / 00223980.2016 .1182888$

Baptiste, D., Fecher, A. M., Dolejs, S. C., Yonder, J., Schmidt, C. M., Couch, M. E., \& Ceppa, D. P. (2017). Gender differences in academic surgery, work-life balance, and satisfaction. Journal of Surgical Research, 218, 99-107. doi.org/10.1016/j.jss.2017.05.075

Barnes, C. M., Wagner, D. T., \& Ghumman, S. (2012). Borrowing from sleep to pay work and family: Expanding time-based conflict to the broader nonwork domain. Personnel Psychology, 65(4), 789-819. doi:10.1111/peps.12002 
Baltes, B., Zhdanova, L., \& Clark, M. (2011). Examining the relationships between personality, coping strategies, and work-family conflict. Journal of Business \& Psychology, 26(4), 517-530. doi:10.1007/s10869-010-9207-0

Bear, J. B., Cushenbery, L., London, M., \& Sherman, G. D. (2017). Performance feedback, power retention, and the gender gap in leadership. Leadership Quarterly, 28(6), 721-740. doi:10.1016/j.leaqua.2017.02.003

Berthelsen, H., Hakanen, J. J., \& Westerlund, H. (2018). Copenhagen Psychosocial Questionnaire - A validation study using the Job Demand-Resources model. Plos ONE, 13(5), 1-17. doi:10.1371/journal.pone.0196450

Bjørnstad, S., Patil, G. G., \& Raanaas, R. K. (2016). Nature contact and organizational support during office working hours: Benefits relating to stress reduction, subjective health complaints, and sick leave. Work, 53(1), 9-20. doi:10.3233/WOR-152211

Boatwright, K. J., \& Egidio, R. K. (2003). Psychological predictors of college women's leadership aspirations. Journal of College Student Development, 44(5), 653-669.

Bolino, M. C., Hsiung, H., Harvey, J., \& LePine, J. A. (2015). 'Well, I'm tired of tryin'!' Organizational citizenship behavior and citizenship fatigue. Journal of Applied Psychology, 100(1), 56-74. doi:10.1037/a0037583

Bourhis, A., \& Mekkaoui, R. (2010). Beyond work-family balance: Are family-friendly organizations more attractive? Relations Industrielles / Industrial Relations, 65(1), 98117.

Bowling, N. A., Alarcon, G. M., Bragg, C. B., \& Hartman, M. J. (2015). A meta-analytic examination of the potential correlates and consequences of workload. Work \& Stress, 29(2), 95-113. doi:10.1080/02678373.2015.1033037

Boyar, S. L., Carr, J. C., Mosley Jr., D. C., \& Carson, C. M. (2007). The development and validation of scores on perceived work and family demand scales. Educational \& Psychological Measurement, 67(1), 100-115. doi:10.1177/0013164406288173

Braun, S., \& Peus, C. (2018). Crossover of work-life balance perceptions: Does authentic leadership matter? Journal of Business Ethics, 149(4), 875-893. doi:10.1007/s10551-0163078-x

Brue, K. L., \& Brue, S. A., (2018). Leadership role identity construction in women's leadership development programs. Journal of Leadership Education, 17(1), 7-27. doi:10.12806/V17/I1/C2

Carlson, D. S., Ferguson, M., Kacmar, K. M., Grzywacz, J., \& Whitten, D. (2011). Pay it forward: The positive crossover effects of supervisor work-family enrichment. Journal of Management, 37(3), 770-789. doi:10.1177/0149206310363613 
Carlson, D. S., Grzywacz, J. G., \& Zivnuska, S. (2009). Is work-family balance more than conflict and enrichment? Human Relations, 62(10), 1459-1479. doi:10.1177/0018726709336500

Carlson, D. S., Kacmar, K. M., \& Williams, L. J. (2000). Construction and initial validation of a multidimensional measure of work-family conflict. Journal of Vocational Behavior, 56(2), 249-276. doi:10.1006/jvbe.1999.1713

Chang, A., McDonald, P., \& Burton, P. (2010). Methodological choices in work-life balance research 1987-2006: A critical review. The International Journal of Human Resource Management, 21(13), 2381-2413. doi:10.1080/09585192.2010.516592

Cho, E., \& Tay, L. (2016). Domain satisfaction as a mediator of the relationship between workfamily spillover and subjective well-being: A longitudinal study. Journal of Business \& Psychology, 31(3), 445-457. doi:10.1007/s10869-015-9423-8

Crain, T. L., Hammer, L. B., Bodner, T., Moen, P., Kossek, E. E., Lilienthal, R., \& Buxton, O. M. (2014). Work-Family Conflict, Family-Supportive Supervisor Behaviors (FSSB), and sleep outcomes. Journal of Occupational Health Psychology, 19(2), 155-167. doi:10.1037/a0036010

Debebe, G. (2011). Creating a safe environment for women's leadership transformation. Journal of Management Education, 35(5), 679-712. doi:10.1177/1052562910397501

Desrochers, S., Hilton, J. M., \& Larwood, L. (2005). Preliminary validation of the work-family integration-blurring scale. Journal of Family Issues, 26(4), 442-466. doi:10.1177/0192513X04272438

DiRenzo, M. S., Greenhaus, G. H., \& Weer, C. H. (2011). Job level, demands, and resources as antecedents of work-family conflict. Journal of Vocational Behavior, 78(2), 305-314. doi:10.1016/j.jvb.2010.10.002

DiRenzo, M. S., Greenhaus, G. H., \& Weer, C. H. (2015). Relationship between protean career orientation and work-life balance: A resource perspective. Journal of Organizational Behavior, 78, 538-560. doi:10.1002/job.1996

Donnelly, K., Twenge, J. M., Clark, M. A., Shaikh, S. K., Beiler-May, A., \& Carter, N. T. (2016). Attitudes toward women's work and family roles in the United States, 19762013. Psychology of Women Quarterly, 40(1), 41-54. doi:10.1177/0361684315590774

Dutta, D. (2018). Women's discourses of leadership in STEM organizations in Singapore: Negotiating sociocultural and organizational norms. Management Communication Quarterly, 32(2), 233-249. doi:10.1177/0893318917731537 
Ely, R. J., Ibarra, H., \& Kolb, D. M. (2011). Taking gender into account: Theory and design for women's leadership programs. Academy of Management Learning \& Education, 10(3), 474-493. doi:10.5465/amle.2010.0046

Emslie, C., \& Hunt, K. (2009). 'Live to work' or 'work to live'? A qualitative study of gender and work-life balance among men and women in mid-life. Gender, Work and Organization, 16(1), 151-172. doi:10.1111/j.1468-0432.2008.00434.x

Ferguson, M., Carlson, D., Kacmar, K. M., \& Halbesleben, J. B. (2016). The supportive spouse at work: Does being work-linked help? Journal of Occupational Health Psychology, 21(1), 37-50. doi:10.1037/a0039538

French, K. A., Dumani, S., Allen, T. D., \& Shockley, K. M. (2018). A meta-analysis of workfamily conflict and social support. Psychological Bulletin, 144(3), 284-314. doi:10.1037/bul0000120

Greenhaus, J. H., \& Beutell, N. J. (1985). Sources of conflict between work and family roles. Academy of Management Review, 10, 76-88. Retrieved from http://www.aomonline.org/

Greenhaus, J. H., \& Powell, G. N. (2006). When work and family are allies: A theory of workfamily enrichment. Academy of Management Review, 31(1), 72-92. Retrieved from http://www.aom.pace.edu/amr/

Gregory, A., \& Milner, S. (2009). Editorial: Work-life balance: A matter of choice? Gender, Work and Organization, 16(1), 1-13. doi:10.1111/j.1468-0432.2008.00429.x

Hakanen, J. J., Peeters, M. W., \& Perhoniemi, R. (2011). Enrichment processes and gain spirals at work and at home: A 3-year cross-lagged panel study. Journal of Occupational \& Organizational Psychology, 84(1), 8-30. doi:10.1111/j.2044-8325.2010.02014.x

Halbesleben, J. B. (2010). Spousal support and coping among married coworkers: Merging the transaction stress and Conservation of Resources models. International Journal of Stress Management, 17(4), 384-406. doi:10.1037/a0020500

Halbesleben, J. B., Zellars, K. L., Carlson, D. S., Perrewé, P. L., \& Rotondo, D. (2010). The moderating effect of work-linked couple relationships and work-family integration on the spouse instrumental support-emotional exhaustion relationship. Journal of Occupational Health Psychology, 15(4), 371-387. doi:10.1037/a0020521

Harrison, S. H., \& Wagner, D. T. (2016). Spilling outside the box: The effects of individuals' creative behaviors at work on time spent with their spouses at home. Academy of Management Journal, 59(3), 841-859. doi:10.5465/amj.2013.0560

Hilbrecht, M., Shaw, S., Johnson, L., \& Andrey, J. (2008). 'I'm home for the kids': Contradictory implications for work-life balance of teleworking mothers. Gender, Work and Organization, 15(5), 454-476. doi:10.1111/j.1468-0432.2008.00413.x 
Hobfoll, S. E. (1989). Conservation of resources: A new attempt at conceptualizing stress. American Psychologist, 44(3), 513-524. doi:10.1037/0003-066X.44.3.513

Hobfoll, S. E. (2001). The influence of culture, community, and the nested self in the stress process: Advancing Conservation of Resources theory. Applied Psychology: An International Review, 50(3), 337-370. Retrieved from http://onlinelibrary.wiley.com/journal/10.1111/(ISSN)1464-0597

Hunter, E. M., Perry, S. J., Carlson, D. S., \& Smith, S. A. (2010). Linking team resources to work-family enrichment and satisfaction. Journal of Vocational Behavior, 77(2), 304312.

Jiang, H., Luo, Y., \& Kulemeka, O. (2017). Strategic social media use in public relations: Professionals' perceived social media impact, leadership behaviors, and work-life conflict. International Journal of Strategic Communication, 11(1), 18-41. doi:10.1080/1553118X.2016.1226842

Kaliannan, M. \& Perumal, K. \& Dorasamy, M. (2016). Developing a work-life balance model towards improving job satisfaction among medical doctors across different generations. The Journal of Developing Areas, 50(5), 343-351. doi:10.1353/jda.2016.0035

Kalysh, K., Kulik, C. T., \& Perera, S. (2016). Help or hindrance? Work-life practices and women in management. Leadership Quarterly, 27(3), 504-518.

doi:10.1016/j.leaqua.2015.12.009

Karatepe, O. M., \& Olugbade, O. A. (2009). The effects of job and personal resources on hotel employees' work engagement. International Journal of Hospitality Management, 28(4), 504-512. doi:10.1016/j.ijhm.2009.02.003

Karkoulian, S., Srour, J., \& Sinan, T. (2016). A gender perspective on work-life balance, perceived stress, and locus of control. Journal of Business Research, 69(11), 4918-4923. doi:10.1016/j.jbusres.2016.04.053

Kinnunen, U., Feldt, T., Mauno, S., \& Rantanen, J. (2010). Interface between work and family: A longitudinal individual and crossover perspective. Journal of Occupational \& Organizational Psychology, 83(1), 119-137.

Kossek, E. E. (2016). Implementing organizational work-life interventions: toward a triple bottom line. Community, Work \& Family, 19(2), 242-256. doi:10.1080/13668803.2016.1135540

Kramer, A., \& Wonjoon, C. (2015). Work demands, family demands, and BMI in dual-earners families: A 16-year longitudinal study. Journal of Applied Psychology, 100(5), 16321640. doi:10.1037/a0038634 
Landers, J. (1981). Quantification in history topic 4: Hypothesis testing II- differing central tendency. Oxford: All Souls College.

Loeffen, O. (2016). Women in senior leadership: What it took to get to the top. New Zealand Journal of Human Resource Management, 16(1), 5-18.

Maertz, C. P., \& Boyar, S. L. (2011). Work-family conflict, enrichment, and balance under "levels" and "episodes" approaches. Journal of Management, 37(1), 68-98. doi:10.1177.0149206310382455

Martin, L. A., Edwards, M., \& Sayers, J. G. (2018). A "novel" discovery: Exploring women’s literary fiction for use in management and leadership education. Academy of Management Learning \& Education, 17(1), 24-40. doi:10.5465/amle.2016.0369

Matthews, R. A., Bulger, C. A., \& Barnes-Farrell, J. L. (2010). Work social supports, role stressors, and work-family conflict: The moderating effect of age. Journal of Vocational Behavior, 76, 78-90. doi:10.1016/j.jvb.2009.06.011

McNall, L. A., Scott, L. D., \& Nicklin, J. M. (2015). Do positive affectivity and boundary preferences matter for work-family enrichment? A study of human service workers. Journal of Occupational Health Psychology, 20(1), 93-104. doi:10.1037/a0038165

McMullan, A. D., Lapierre, L. M., \& Li, Y. (2018). A qualitative investigation of work-familysupportive coworker behaviors. Journal of Vocational Behavior, 107, 25-41, doi:10.1016/j.jvb.2018.03.007

Methot, J. R., \& LePine, J. A. (2016). Too close for comfort? Investigating the nature and functioning of work and nonwork role segmentation preferences. Journal of Business \& Psychology, 31(1), 103-123. doi:10.1007/s10869-015-9402-0

Michel, J. S., \& Clark, M. A. (2009). Has it been affect all along? A test of work-to-family and family-to-work models of conflict, enrichment, and satisfaction. Personality and Individual Differences, 47(3), 163-168. doi:10.1016/j.paid.2009.02.015

Michel, J. S., Mitchelson, J. K., Pichler, S., \& Cullen, K. L. (2010). Clarify relationships among work and family social support, stressors, and work-family conflict. Journal of Vocational Behavior, 76(1), 91-104. doi:10.1016/j.jvb.209.05.007

Morgan, W. B., Perry, S. J. \& Wang, Y. (2018). The angry implications of work-to-family conflict: Examining effects of leadership on an emotion-based model of deviance. Journal of Vocational Behavior, 108, 13-27. doi:10.1016/j.jvb.2018.05.009

Nachar, N. (2008). The Mann-Whitney U: A test for assessing whether two independent samples come from the same distribution. Tutorials in Quantitative Methods for Psychology, 4(1), 13-20. doi:10.20982/tqmp.04.1p013 
Ng, T. H., \& Feldman, D. C. (2014). Embeddedness and well-being in the United States and Singapore: The mediating effects of work-to-family and family-to-work conflict. Journal of Occupational Health Psychology, 19(3), 360-375. doi:10.1037/a0036922

Odle-Dusseau, H. N., Britt, T. W., \& Greene-Shortridge, T. M. (2012). Organizational workfamily resources as predictors of job performance and attitudes: The process of workfamily conflict and enrichment. Journal of Occupational Health Psychology, 17(1), 2840. doi:10.1037/a0026428

Odle-Dusseau, H. N., Hammer, L. B., Crain, T. L., \& Bodner, T. E. (2016). The influence of family-supportive supervisor training on employee job performance and attitudes: An organizational work-family intervention. Journal of Occupational Health Psychology, 21(3), 296-308. doi:10.1037/a0039961

Olsen, J. E., Parsons, C. K., Martins, L. L., \& Ivanaj, V. (2016). Gender diversity programs, perceived potential for advancement, and organizational attractiveness. Group \& Organization Management, 41(3), 271-309. doi:10.1177/1059601115583579

Orbach, R. (2017). Bringing talent off the bench and into the game: The underrepresenteation of women in the boardroom. Fordham Journal of Corporate \& Financial Law, 22(2), 203256.

Paustian-Underdahl, S. C., Halbesleben, J. R. B., Carlson, D. S., \& Kacmar, K. M. (2016). The work-family interface and promotability: Boundary integration as a double-edged sword, Journal of Management, 42(4), 960-981. doi:10.1177/0149206313506464

Phipps, S. S., \& Prieto, L. (2016). A discovery of early labor organizations and the women who advocated work-life balance: An ethical perspective. Journal of Business Ethics, 134(2), 249-261. doi:10.1007/s10551-014-2428-9

Place, K. R., \& Vardeman-Winter, J. (2018). Where are the women? An examination of research on women and leadership in public relations. Public Relations Review, 44(1), 165-173. doi:10.1016/j.pubrev.2017.10.005

Powell, G. N., \& Greenhaus, J. H. (2010). Sex, gender, and decisions at the family $\rightarrow$ Work interface. Journal of Management, 36(4), 1011-1039. doi:10.1177/0149206309350774

Ruderman, M. N., \& Ohlott, P. J. (2005). What coaches of women need to know. Leadership in Action, 25(3), 3-9. doi:/10.1002/lia.1115

Schieman, S., \& Young, M. (2010). Is there a downside to schedule control for the work-family interface? Journal of Family Issues, 31(10). 1391-1414. doi:10.1177/0192513X10361866

Schueller-Weidekamm, C., \& Kautzky-Willer, A. (2012). Challenges of work-life balance physicians/mothers working in leadership positions. Gender Medicine, 9(4), 244-250. doi:/10.1016/j.genm.2012.04.002 
Seiger, C. P., \& Wiese, B. S. (2009). Social support from work and family domains as an antecedent or moderator of work-family conflicts? Journal of Vocational Behavior, 75, 26-37. doi:10.1016/j.jvb.2009.03.001

Siegel, S., \& Castellan, N. J. Jr. (1988). Nonparametric statistics for the behavioral sciences (2nd edition). États-Unis: McGraw-Hill.

Shumaker, S. A., \& Brownell, A. (1984). Toward a theory of social support: Closing conceptual gaps. Journal of Social Issues, 40(4), 11-36.

Siu, O. L., Bakker, A. B., Brough, P., Lu, C., Wang, H., Kalliath, T., .. \& Timms, C. (2013). A three-wave study of antecedents of work-family enrichment: The roles of social resources and affect. Stress \& Health: Journal of the International Society for the Investigation of Stress, 31(4), 306-314.

Steinmetz, H., Frese, M., \& Schmidt, P. (2008). A longitudinal panel study on antecedents and outcomes of work-home interference. Journal of Vocational Behavior, 73(2), 231-241. doi:10.1016/j.jvb.2008.05.002

Tang, G.Tt., Kwan, H. W., Zhang, D. Z., \& Zhu, Z. Z. (2016). Work-family effects of servant leadership: The roles of emotional exhaustion and personal learning. Journal of Business Ethics, 137(2), 285-297.

ten Brummelhuis, L. L., \& van der Lippe, T. (2010). Effective work-life balance support for various household structures. Human Resource Management, 49(2), 173-193. doi: $10.1002 / \mathrm{hrm} .20340$

Tessens, L., White, K., \& Web, C. (2011). Senior women in higher education institutions: Perceived development needs and support. Journal of Higher Education Policy \& Management, 33(6), 653-665. doi:10.1080/1360080X.2011.621191

Toffoletti, K., \& Starr, K. (2016). Women academics and work-life balance: Gendered discourses of work and care. Gender, Work \& Organization, 23(5), 489-504. doi:10.1111/gwao.12133

van Daalen, G., Willemsen, T. M., \& Sanders, K. (2006). Reducing work-family conflict through different sources of social support. (Report). Journal of Vocational Behavior, 69(3), 462476. doi:10.1016/j.jvb.2006.07.005

van der Klis, M., \& Karsten, L. (2009). The commuter family as a geographical adaptive strategy for work-family balance. Community, Work \& Family, 12(3), 339-354.

doi:10.1080/13668800902966372 
van de Voorde, K., Veld, M., \& van Veldhoven, M. (2016). Connecting empowerment-focused HRM and labour productivity to work engagement: The mediating role of job demands and resources. Human Resource Management Journal, 26(2), 192-210. doi:10.1111/1748-8583.12099

Veld, M., van der Heijden, B. M., \& Semeijn, J. H. (2016). Home-to-work spillover and employability among university employees. Journal of Managerial Psychology, 31(8), 1280-1296. doi:10.1108/JMP-09-2015-0347

Webber, M., \& Fendt-Newlin, M. (2017). A review of social participation interventions for people with mental health problems. Social Psychiatry \& Psychiatric Epidemiology, 52(4), 369-380. doi:10.1007/s00127-017-1372-2

Werbel, J. D., \& Danes, S. M. (2010). Work family conflict in new business ventures: The moderating effects of spousal commitment to the new business venture. Journal of Small Business Management, 48(3), 421-440. doi:10.1111/j.1540-627X.2010.00301.x

Williams, J. C., Berdahl, J. L., \& Vandello, J. A. (2016). Beyond work-life "integration". Annual Review of Psychology, 67, 515-539. doi:10.1146/annurev-psych-122414-033710

Winkel, D. E., \& Clayton, R. W. (2010). Transitioning between work and family roles as a function of boundary flexibility and role salience. Journal of Vocational Behavior, 76(2), 336-343. doi:10.1016/j.jvb.2009.10.011

Xin, J. C., Chen, S. S., Kwan, H. W., Chiu, R. R., \& Yim, F. F. (2018). Work-family spillover and crossover effects of sexual harassment: The moderating role of work-home segmentation preference. Journal of Business Ethics, 147(3), 619-629.

Yang, Z. Y., Zhang, H. H., Kwan, H. W., \& Chen, S. S. (2018). Crossover effects of servant leadership and job social support on employee spouses: The mediating role of employee organization-based self-esteem. Journal of Business Ethics, 147(3), 595-604.

Yates, C. A. (2011). Organizing Women in the Spaces between Home, Work and Community. Relations Industrielles / Industrial Relations, 66(4), 585-603.

\section{Author Biography}

Dr. Krystal L. Brue (kbrue@ camonen.edu) is an assistant professor within the Department of Business, Cameron University. Her research focuses on leadership preparation/education, women in leadership, work-life balance, human resource management, and organizational behavior. 